\title{
An ultrastructural study of a nasal haemangioendothelioma
}

\author{
ROBERT M. WILLIAMS AND J. N. THOMAS \\ From the Department of Pathology and Otolaryngology, University of Oxford Medical School, \\ Radcliffe Infirmary, Oxford, UK
}

SUMMARY A malignant haemangioendothelioma of the nose has been examined with the electron microscope. The tumour is predominantly poorly differentiated with only little evidence of its vascular ancestry identified. The cells are polygonal with a wide spectrum of organelles, including microfilaments. A conspicuous feature was the presence of cytoplasmic fenestrae developing into intracytoplasmic vacuolated spaces.

The satisfactory progress of this patient is noted, and the value of electron microscopy in enabling an early and accurate diagnosis of this tumour to be made is emphasised.

Haemangioendothelioma is a rare malignant vascular tumour. It has a wide distribution in the various organs and tissues of the body and may manifest itself at any age. Growth may be rapid or slow and is infiltrative in character. Metastases are frequent and generally blood-borne, although occasionally there may be lymphatic spread. Farr et al. (1970) report on 21 patients with malignant vascular tumours of the head and neck region seen during a 39-year period between 1930 and 1969. Ten of these were classified as angiosarcoma, one of which occurred in the maxillary antrum. Other sporadic case reports of haemangioendothelioma in the nose and paranasal sinus have been recorded (McClatchey et al., 1976).

The ultrastructural appearances of malignant haemangioendothelioma have rarely been reported. Rosai et al. (1976), Steiner and Dorfman (1972), and Ramsey (1966) have reviewed cases in the skin, bone, and spinal cord. Their histological descriptions are broadly similar. Complex vascular channels are described which are lined by atypical and florid outgrowths of endothelium. In places this is so profuse as to obscure the vessel lumen. Chronic inflammatory cells sometimes mingle with tumour tissue. The better differentiated tumours are characterised by plump pleomorphic endothelial cells which rest on a prominent basal lamina. At the ultrastructural level pinocytotic vesicles, filaments, prominent granular endoplasmic reticulum, glycogen, lysosomes, and occasional Weibel-Palade

Received for publication 16 November 1978 bodies tend to be relatively more conspicuous than in normal endothelium. In addition, fine cytoplasmic processes are noticeable and, in places, related to intracellular vesicles. The more anaplastic tumours lacked vessel luminal organisation; any lumen present tended to be squeezed out of existence by polygonal cells. In those cases of anaplastic haemangioendothelioma in which ultrastructural studies have been made there is a smaller spectrum of organelles.

The present report provides the first description at the ultrastructural level of a nasal malignant haemangioendothelioma.

\section{Case history}

A 41-year-old transport driver presented with a severe pain felt over and behind the left eye which had developed over a period of one week. The condition was originally diagnosed and treated as frontal sinusitis without relief of symptoms. Over the next month the patient noticed a tender swelling developing on the medial side of the eye; he also complained of increasing left nasal obstruction and had suffered three minor nose bleeds.

At an ENT consultation a tender, firm swelling was palpable above the left medial canthus of the eye. The globe of the eye was slightly proptosed and displaced laterally. There was a friable tumour in the upper part of the left nasal cavity. A biopsy of this was conspicuously bloody; material was taken for both light and electron microscopy. The extent of the tumour was revealed by computerised axial tomography. A soft-tissue mass filled the left 
Fig. 1 A tissue fragment with narrow sheets of sarcomatous endothelial cells. In some areas there is vascular luminal clefting between these cells and the stroma. Inset: see Fig. 2. Haematoxylin and eosin $\times 75$.

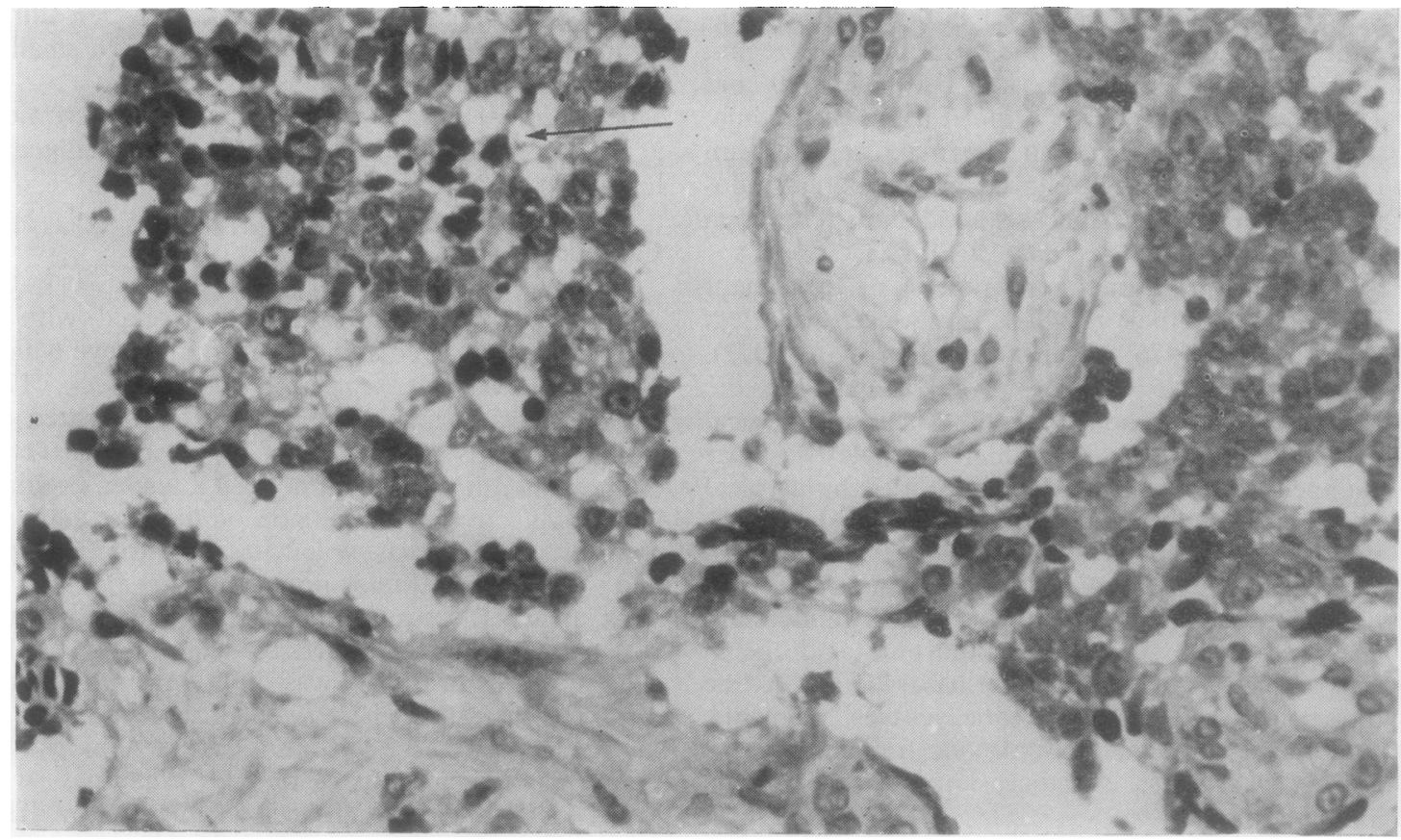

Fig. 2 Inset Fig. 1. Many of the endothelial cells have pronounced vacuolation (arrow) better seen in the electron micrograph (Fig. 5). Some lymphocytes pervade the tissue. $H$ and $E \times 195$. 


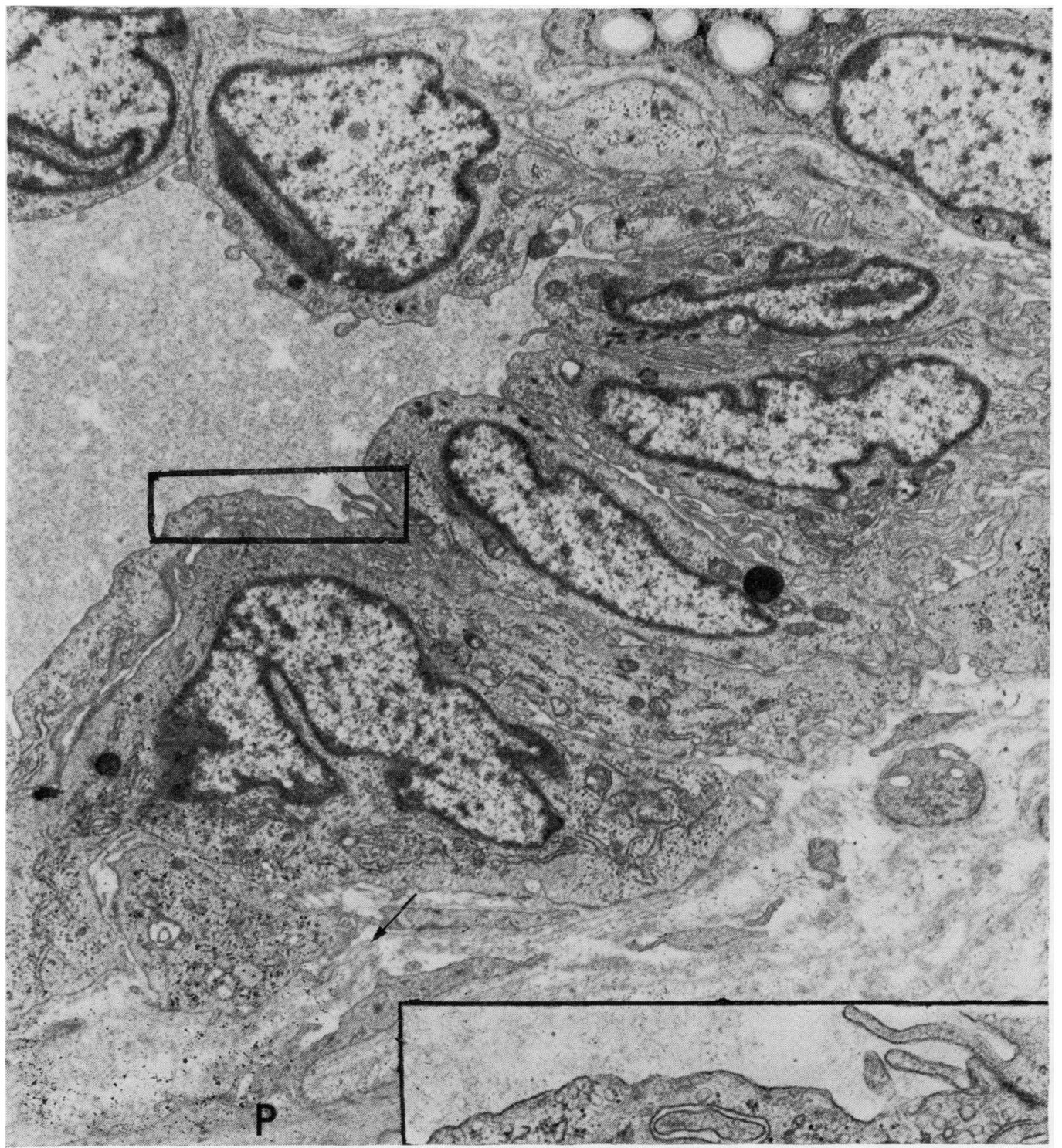

Fig. 3 The vessel has a prominent plump endothelium which rests on a reduplicated basement membrane (arrow). Fine cytoplasmic processes protrude into the lumen (see inset). Pericytes $(P)$ are also noted. $\times 8000$. Inset: Tight junction and micropinocytotic vesicles evident.

nasal cavity and ethmoid sinuses and extended posteriorly into the nasopharynx. There was extension into the orbit with displacement of the globe anteriorly and laterally. Conventional tomography showed bone erosion of both sides of the nasal cavity, the left orbit, and the floor of the anterior cranial fossa. There was no evidence of metastatic spread.
Because of the site and extent of the lesion, surgical removal was deemed impossible, and treatment by a combination of chemotherapy and radiotherapy was initiated. The Price-Hill chemotherapy regime was used. This is a schedule of different chemotherapeutic agents given in sequence designed on a cellular kinetic basis to achieve partial tumour synchrony. The treatment is given in two 


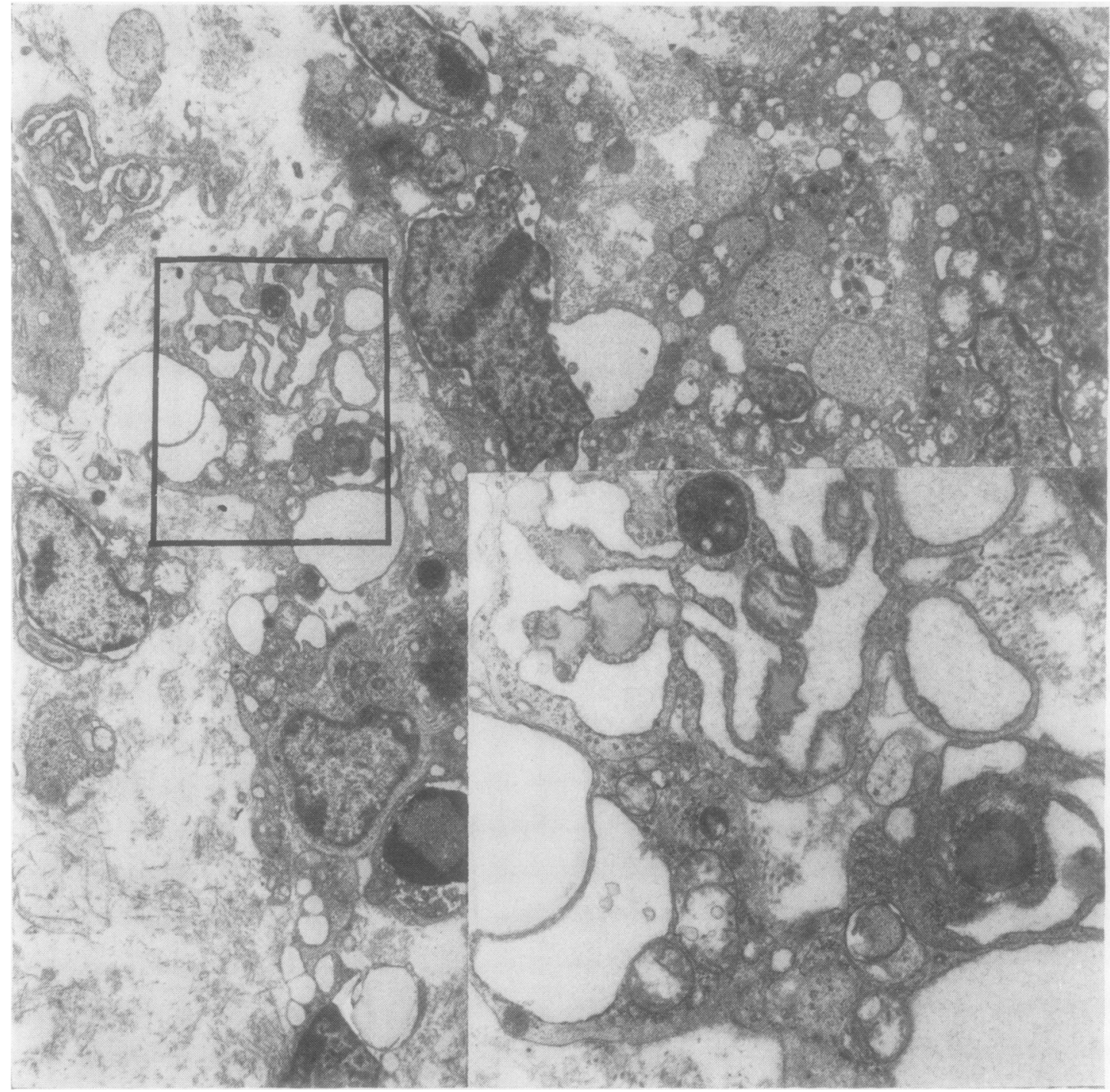

Fig. 4 Endothelial cells displaying a complex, fenestrated web of cytoplasmic outgrowths, producing a caveolated or vacuolated cytoplasm. $\times$ 5750. Inset: detail $\times 16300$.

stages. A first stage as an inpatient was given as two courses separated by an interval of two weeks. Following this, external irradiation of 5100 rads was given to the left nasal cavity and paranasal sinuses. The second phase of chemotherapy, given as an outpatient, followed radiotherapy and comprised six treatments at three-weekly intervals. The drugs involved were vincristine, bleomycin, methotrexate, hydrocortisone, and 5-fluoro-uracil. Folinic acid was administered 24 hours after the course to reduce the possibility of bone marrow suppression.
There was a notable response to the first phase of chemotherapy with regression of tumour and relief of pain. This was maintained throughout the period of radiotherapy but there was a recurrence shortly after this had finished with expansion of tumour and return of pain. When the second phase of chemotherapy was started further regression of tumour and relief of pain was achieved. Ten months after treatment the patient remained symptom-free with no tumour visible in the nasal cavity. A repeat computerised axial tomography scan at 
this time confirmed total regression of the tumour.

\section{Material and methods}

The small curetted fragments were fixed in both neutral formalin and glutaraldehyde for light and electron microscopic examination. Material for light microscopy was stained with haematoxylin and eosin, and reticulin was demonstrated by the Gordon and Sweet technique, including nuclear-fast red counterstaining. Tissue for electron microscopy was post-fixed in osmium tetroxide and embedded in Araldite, and ultrathin sections were cut and stained with uranyl acetate and lead citrate. Grids were examined with a Philips EM300 electron microscope operated at $60 \mathrm{kV}$.

\section{Results}

LIGHT AND ELECTRON MICROSCOPIC OBSERVATIONS

The tumour tissue was composed of fibrocellular fragments in which were closely packed, irregular sheets of basophilic, polygonal cells. A vague vascular outline was maintained in places, although in the main this had been eliminated by proliferating sheets of tumour cells which had clearly abandoned the function of defining vascular spaces (Fig. 1). The original, though now inconspicuous, vascular pattern was best demonstrated by a reticulin preparation in which the sarcomatous endothelium is enclosed on the luminal side by reticulin. Many tumour cells had cytoplasmic vacuolation (Fig. 2). A conspicuous feature was the presence of lymphocytes widely scattered throughout the tumour tissue (Fig. 2). Although much of the tumour was poorly differentiated, some areas did reveal a better differentiated pattern when examined with the electron microscope. These areas include vessels with a lining of polygonal and columnar endothelial cells, which rest against a reduplicated basement membrane and are connected in many areas by tight junctional complexes (Fig. 3). Osmiophilic dense bodies and glycogen are prominent, and there is some trend towards cytoplasmic membrane outgrowths and pinocytotic vesicle formation (Fig. 3). Pericyte processes are found insinuated between the reduplicated basement membrane (Fig. 3). The major portion of tumour showed no resemblance to or derivation from blood vessels. It had two broad patterns: those characterised by pleomorphic cells loosely aggregated, and those compacted into a tight pavement fashion. Intermediate forms were also noted.

Those cells that were loosely aggregated were made conspicuous by the presence of cytoplasmic out- and in-foldings which produced numerous intracytoplasmic vacuoles (Fig. 4). Glycogen, ribosomal rosettes, lysosomes, osmiophilic dense bodies, pinocytotic vesicles, and microfilaments also figured to different degrees within the cells. Further, in many regions erythrocytes had infiltrated between tumour cells. In general, the tumorous areas were demarcated from the surrounding fibrocellular stroma by a dense, collagenous band which included many pericyte-like processes. The overall cellular architecture progressed from the loosely cellular to the compact (Fig. 5). Despite this alteration, the cytoplasmic structure was in essence similar. Slight variations included decreased nuclear heterochromasia and increased glycogen and free ribosomal particles.

\section{Discussion}

From the histological point of view the tumour has classic appearances with a spectrum of changes from well to poorly differentiated. A vascular pattern is maintained by the well differentiated tumour and is characterised by plump elongated endothelial cells resting on a reduplicated basement membrane. There are some endothelial cytoplasmic outgrowths but no intracytoplasmic vacuolation. The poorly differentiated tumour has lost its vascular identity, and there is a succession of cellular patterning from loosely aggregated cells to compact polygonal forms. A pertinent negative observation was the absence of Weibel-Palade bodies, reflecting perhaps the general undifferentiated nature of this tumour. Many erythrocytes are insinuated between the more loosely arranged cells. A characteristic and diagnostic feature of the less differentiated tumour, which is easily visible with light microscopy, is the presence of intracellular vacuolated spaces associated in many areas with cytoplasmic outgrowths and fenestrae (Fig. 4). The significance of these has been reviewed by Rosai et al. (1976). One theory is that they represent some intracytoplasmic attempt at lumen formation analogous to the intracellular caveolated spaces found in many adenocarcinomata, but with which they should not be confused.

The treatment of choice for haemangioendothelioma is regarded as complete surgical excision. In this case surgery was not possible because of the site and extent of the tumour. A combination of chemotherapy and radiotherapy was used to bring about fibrosis and shrinkage of the tumour and so produce relief of symptoms. The treatment was regarded as palliative and the overall prognosis poor. Previously reported treatment with chemotherapy using single agents has been notably unsuccessful. The favourable response of this tumour to 


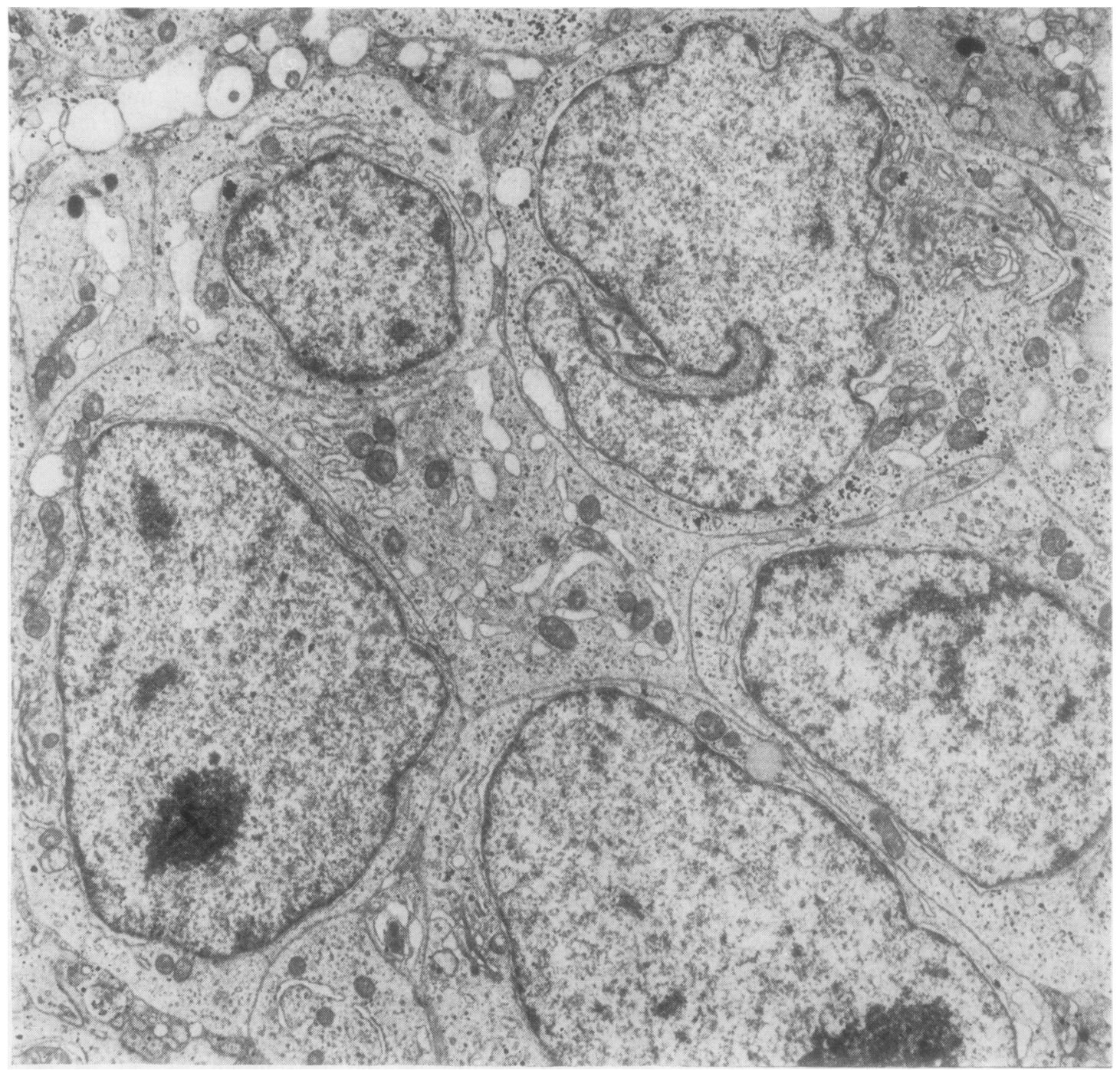

Fig. 5 The cells are very compact with little intercellular spacing. Mitochondria, glycogen, cytoplasmic vesicles, and cisternae of granular endoplasmic reticulum are prominent. $\times 9200$.

a multiple drug regime such as the Price-Hill schedule has not been reported previously (Price and Hill, 1977). This provides some grounds for optimism in the management of inoperable tumours and emphasises the importance of an early and accurate diagnosis which can best be achieved by the use of electron microscopy.

We thank Professor J. O'D. McGee for the use of the electron microscope, $\mathrm{Mr} \mathrm{D}$. Jerrome and $\mathrm{Dr}$
T. M. Parry for the micrographs, and Mrs R. Hunt for the typescript.

\section{References}

Farr, H. W., Carandang, C. M., and Huvos, A. G. (1970). Malignant vascular tumors of the head and neck. American Journal of Surgery, 120, 501-504.

McClatchey, K. D., Batsakis, J. G., Rice, D. H., and Olson, N. R. (1976). Angiosarcoma of the maxillary sinus: report of case. Journal of Oral Surgery, 34, 1019-1021. 
Price, L. A., and Hill, B. T. (1977). A kinetically based logical approach to the chemotherapy of head and neck cancer. Clinical Otolaryngology, 2, 339-345.

Ramsey, H. J. (1966). Fine structure of hemangiopericytoma and hemangioendothelioma. Cancer, 19, 2005-2018.

Rosai, J., Sumner, H. W., Kostianovsky, M., and Perez-Mesa, C. (1976). Angiosarcoma of the skin: a clinicopathologic and fine structural study. Human
Pathology, 7, 83-109.

Steiner, G. C., and Dorfman, H. D. (1972). Ultrastructure of hemangioendothelial sarcoma of bone. Cancer, 29, 122-135.

Requests for reprints to: Dr R. M. Williams, University Department of Pathology, Gibson Laboratories, Radcliffe Infirmary, Oxford OX2 6HE, UK.

\section{The April 1979 Issue}

\section{THE APRIL 1979 ISSUE CONTAINS THE FOLLOWING PAPERS}

Identification of the paraproteins and clinical significance of more than one paraprotein in serum of 56 patients MARTIN E. GORE, PAMELA G. RICHES, AND J. KOHN

Serum cystyl aminopeptidase activity in the 36th week of pregnancy B. H. DURHAM AND R. E. REWELL

Total and free thyroid hormone concentrations after elective surgery R. W. G. PRESCOTT, P. P. B. YEO, M. J. WATSON, I. D. A. JOHNSTON, J. G. RATCLIFFE, AND D. C. EVERED

Studies of plasma zinc, copper, caeruloplasmin, and growth hormone G. S. ANDREWS

A case of $\gamma 3$ heavy chain disease with vacuolated plasma cells: a clinical, immunological, and ultrastructural study WALTER FEREMANS, MICHEL CAUDRON, AND CLAUDE BIEVA

Evaluation of T and B lymphocytes in liver infiltrates of patients with chronic active hepatitis SILVIA FARGION, GABRIELE SANGALLI, GUIDO RONCHI, AND GEMINO FIORELLI

Progression of hepatitis non-A, non-B to chronic active hepatitis STEN IWARSON, JOHAN LINDBERG, AND PER LUNDIN

Haematological features of angioimmunoblastic lymphadenopathy with dysproteinaemia $R$. L. BREARLEY, J. CHAPMAN, M. H. CULLEN, M. A. HORTON, A. G. STANSFELD, AND A. H. WATERS

Rapid cytological diagnosis of basal cell carcinoma of the skin CHRISTOPHER L. BROWN, MICHAEL R. KLABER, AND M. GILLIAN ROBERTSON

An immunohistochemical study of the significance of HCG secretion by large bowel adenocarcinomata C. H. BUCKLEY AND H. FOX
Alpha-1-antitrypsin deficiency and hepatocellular carcinoma J. K. KELLY, J. S. DAVIES, AND ALED W. JONES

Viral exposure and abnormal liver function in haemophilia B. A. MCVERRY, M. G. R. ROSS, WENDY A. KNOWLES, AND JENNIFER VOKE

Limits to progressive reduction of resident skin bacteria by disinfection H. A. LILLY, E. J. L. LOWBURY, AND M. D. WILKINS

Particle size distribution analysis for the rapid detection of microbial infection of urine C. S. DOW, A. D. FRANCE, M. S. KHAN, AND T. JOHNSON

Detection of bacterial phosphatase activity by means of an original and simple test G. SATTA, G. GRAZI, P. E. VARALDO, AND R. FONTANA

Classification of staphylococci isolated from ocular tissues V. M. MAHAJAN

Antibodies to germinating and yeast cells of Candida albicans in human and rabbit sera Y. M. HO, MUN H. NG, AND C. T. HUANG

\section{Technical methods}

A simplified rapid method for purification of glomeruli J. L. PORTIS, S. S. WIKEL, AND F. J. MCATEE

A modified device for replica plating KENT CROSSLEY AND KAREN MEAD

Letters to the Editor

Book reviews

Association of Clinical Pathologists: 102nd Scientific Meeting

Copies are still available and may be obtained from the PUBLISHING MANAGER, BRITISH MEDICAL ASSOCIATION, TAVISTOCK SQUARE, LONDON WC1H 9JR, price $£ 3.00$, including postage 